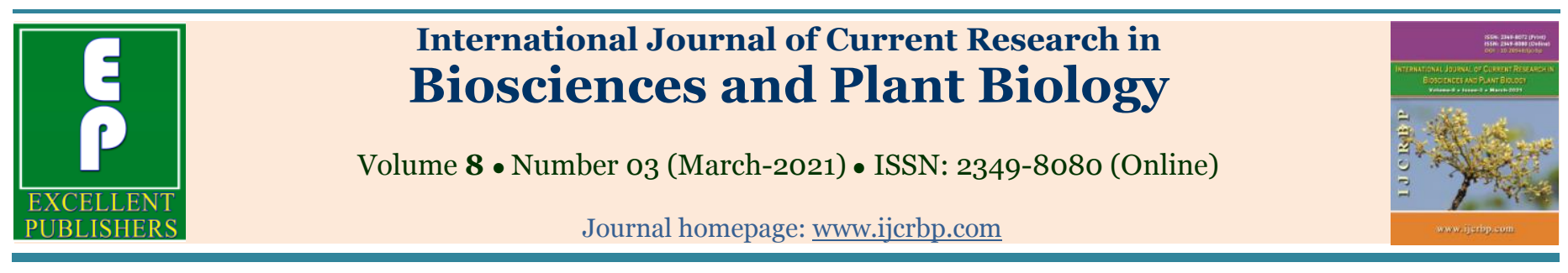

\title{
Effect of biofertilizers on growth, photosynthetic and biochemical parameters of tomato (Lycopersicon esculentum Mill.)
}

\author{
S. Prabakaran ${ }^{1}$, R. Bakiyaraj ${ }^{1}$, L. Baskaran ${ }^{10}{ }^{2}$, T. Mahakavi $^{1}$ \\ ${ }^{I}$ Department of Botany, Government Arts College (Autonomous), Karur, Tamil Nadu, India \\ ${ }^{2}$ Department of Botany, Government Arts College (Autonomous), Salem-636 007, Tamil Nadu, India \\ *Corresponding author; e-mail: drprabakarans@gmail.com
}

\begin{abstract}
Article Info
Keywords:

Biochemical parameters

Biofertilizers

Crop morphology

Inoculation

Tomato

Abstract

The biofertilizers are commonly called as microbial inoculants which are capable of mobilizing important nutritional elements in the soil from non-usable to usable form by the crop plants through their biological processes. The present investigation was carried out to study the application of soil organic amendments Azospirillum, Rhizobium, Phosphobacteria and Pseudomonas fluorescens significantly increased morphological, photosynthetic and biochemical parameters on tomato (Lycopersicon esculentum Mill.) at all growth stages. It can be concluded that biofertilizer manure can be used for quick stabilization of soil fertility as well as biological activities, which is in turn help in nutrient availability during transition periods. Finally, it was observed that the plants treated with experimental biofertilizer Rhizobium showed excellent results in the morphological and biochemical parameters as compared to the other biofertilizers and also control.
\end{abstract}

- Received: 09 January 2021 • Revised: 20 February 2021 • Accepted: 23 February 2021 • Published Online: 6 March 2021

\section{Introduction}

Biofertilizer is a community of bacteria inhabiting the rhizosphere region or in plant tissues that can serve as biocontrol agents for pathogens and stimulate plant growth to increase crop growth and yield (Yadav et al., 2017). The results of previous studies report that biological fertilizers from the Bacillus spp. and Pseudomonas spp. able to dissolve phosphate (Ilyas et al., 2014). In addition to the biofertilizers, the use of organic fertilizers can also reduce the application of chemical fertilizers to a great extent. With the increasing interest in using renewable energy, the production and subsequent use of biomass energy is an important organic source (Zheng et al., 2016). Biogas slurry is one of the best organic fertilizers to revitalize soils, since it is a rich source of both plant nutrients and organic matter.

Organic fertilization is very important in organic fruit production due to use of inorganic fertilizers is not possible. Therefore $\mathrm{N}_{2}$-fixing and phosphate solubilising bacteria, including Bacillus, Azotobacter, Azospirillum, Beijerinckia and Pseudomonas are widely used in organic plant growing. Organic farming is a new agricultural production system involves locally and naturally available organic materials or agro-inputs to meet out the production system without endangering our precious natural resources (Mie et al., 2017). Organic agriculture combines tradition, innovation and science 
to benefit the shared environment and promote fair relationships and a good quality of life for all involved.

Tomato (Lycopersicon esculentum Mill.) belongs to family Solanaceae, is one of the popular vegetables of great commercial value and is used in various forms. This is one of the most popular and second largest producers of the vegetable in the world. Tomato occupies large scale cultivation in India with an average production of $4.6 \mathrm{MT}$ per year. It contains higher quantity of total sugar starch and minerals like potassium, calcium, sodium, magnesium, phosphorus, boron, manganese, zinc, copper, iron, etc. Apart from this it also contains organic acids such as citric, malic and acetic acid which are known as health acids in fresh tomato fruit.

In this experiment, there are number of microbial inoculants used as biofertilizers. They include Azospirillum, Phosphobacteria, Rhizobium and Pseudomonas fluorescens, which have been given much attention as they are responsible to plant growth and development of crops under pot culture inoculation. In the present investigation, the effects of biofertilizers were studied separately to establish the growth, morphological and biochemical effects on $L$. esculentum.

\section{Materials and methods}

\section{Seed material}

The seeds of tomato were collected from collected from the Regional Agricultural Research Station, Karur-639 005, Tamil Nadu.

\section{Details of treatment}

The experiment was laid down in a pot culture with three replications and five treatments. Treatment details without amendments (Control, Azospirillum, Phosphobacteria, Rhizobium and Pseudomonas fluorescens. The experiment conducted in sandy loam soil of botanical garden, PG Research and Department of Botany, Government Arts College, Karur, Tamil Nadu.

\section{Design and layout}

The experiment was laid out in randomized block design (RPD) with three replication and five treatments.
Each pot contain total amount of $6 \mathrm{~kg}$ with respective amount of Azospirillum, Rhizobium, Phosphobacteria and Pseudomonas fluorescens in soil. The respective amount of soil amendments were applied at the time of filling of soil into the pot.

\section{Observations and its methods}

The plants were watered at regular interval and the growth and bio chemical parameters were recorded after 15 and 30 days of sowing. The morphological parameters such as germination percentage, shoot \& root length, fresh \& dry weights were measured. The photosynthetic and biochemical parameters such as chlorophyll 'a' and chlorophyll 'b' (Arnon, 1949), total protein content (Lowry et al., 1951), total sugar (Nelson, 1944) and total starch content (Dubois et al., 1956) were analyzed.

\section{Results and discussion}

The data of germination percentage showed increase due to various treatments as compared to control (Fig. $1)$. The maximum germination percentage $(90 \%)$ was obtained in treatment Rhizobium, Phosphobacteria amendments followed Azospirillum (84\%) and Pseudomonas fluorescens (82\%), which was significantly over control. This result agreed with the result of Reddy et al. (2018) which affirmed that soil inoculation with NPK $75 \mathrm{~kg} / \mathrm{ha}+$ Azotobacter sp. + Azospirillum sp increased okra crop seed germination, shortened the period between sowing and transplanting by 7 days, increased the yield.

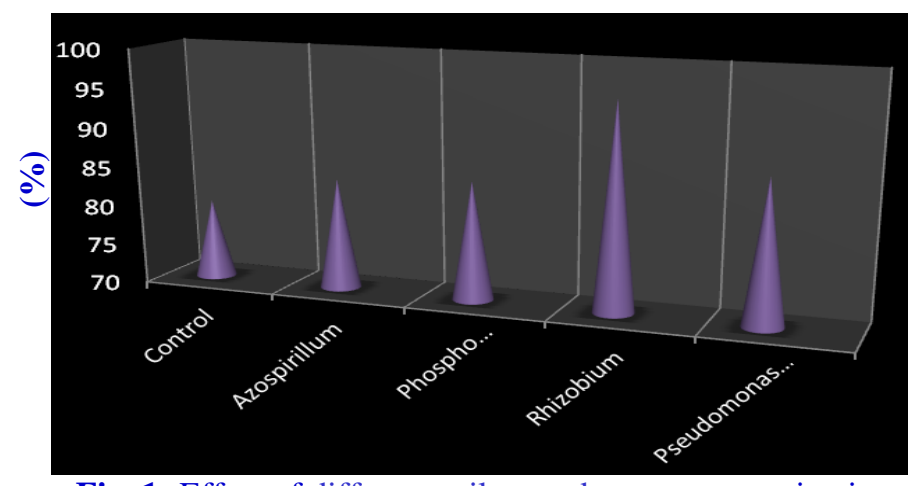

Fig. 1: Effect of different soil amendments on germination percentage of L. esculentum.

The shoot length and root length recorded increase due to application of Azospirillum, Phosphobacteria, Rhizobium and Pseudomonas fluorescens over control (Figs. 2A and 2B). Maximum shoot and root length was 
observed in single application of soil amendment Rhizobium on 15 and 30 DAS with respect to control. Minimum shoot and root length was recorded from the untreated plants. The result is in line with the finding Nalawde and Bhalerao (2015), who reported that the significant increase in growth parameter of black gram (Vigna mungo L.). Their morphological parameters such as number of leaves, length of leaves, breath of leaves, length of plants, shoot length, root length and total length of plant showed significant increase.

The data on Figs. 3A and 3B, the fresh weight and dry weight of tomato plant on 15 and 30 DAS, as a result, Rhizobium treatment alone gave significantly higher fresh weight and dry weight compared to control and also other treatments. This resulted due to the improved growth status of plants because of the presence of organic amendments in the soil. Our result is supported by Farfour (2013) who reported that, inoculation of faba bean with rhizobial strain caused noticeable increase in plant length, fresh weight and dry weight. In addition to Sameh et al. (2017) also reported that inoculation of strains increases plants dry weight.

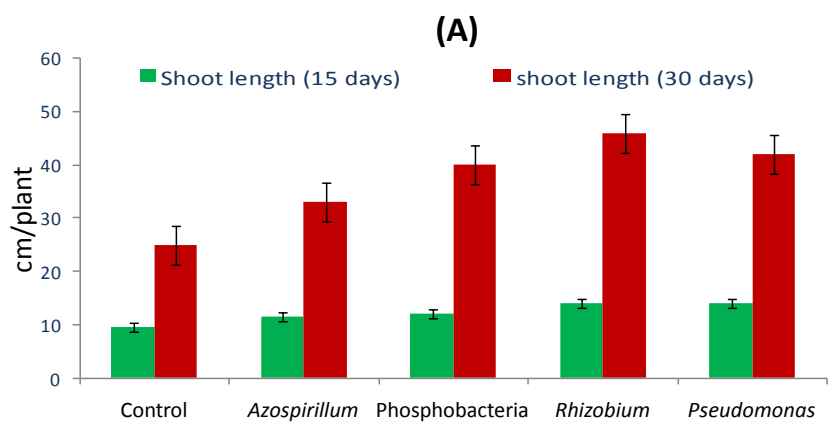

(B)

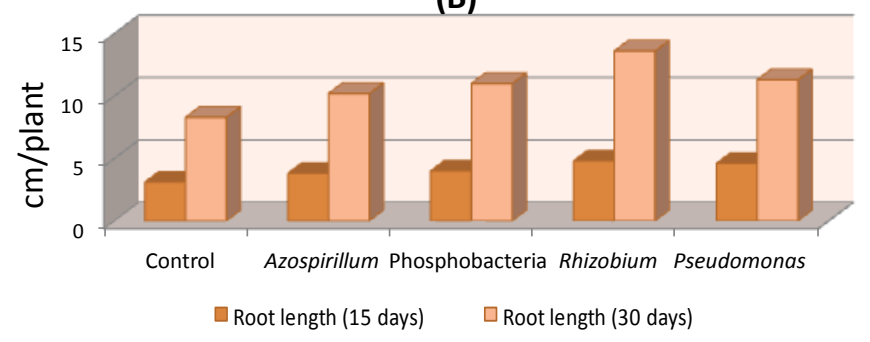

Fig. 2: Effect of different soil amendments on (A) shoot length and (B) root length of L. esculentum.

As it indicated in Figs. 4A and 4B, chlorophyll 'a' and chlorophyll ' $\mathrm{b}$ ' recorded increase due to application of Azospirillum, Phosphobacteria, Rhizobium and Pseudomonas fluorescens over control. Maximum chlorophyll ' $a$ ' and chlorophyll ' $b$ ' was observed in single application of soil amendment Rhizobium on 15 and 30 DAS with respect to control. Minimum chlorophyll ' $a$ ' and chlorophyll ' $b$ ' was recorded from the untreated plants. This is in line with the results of Kalaiarasi and Sivakumar (2014) who documented that the chlorophyll content was increased in Phaseolus vulgaris $\mathrm{L}$. the chlorophyll content was increased in combined inoculation of Rhizobium sp., Phosphobacteria, Azotobacter sp. and Azospirillum sp. treatments than in control plants.
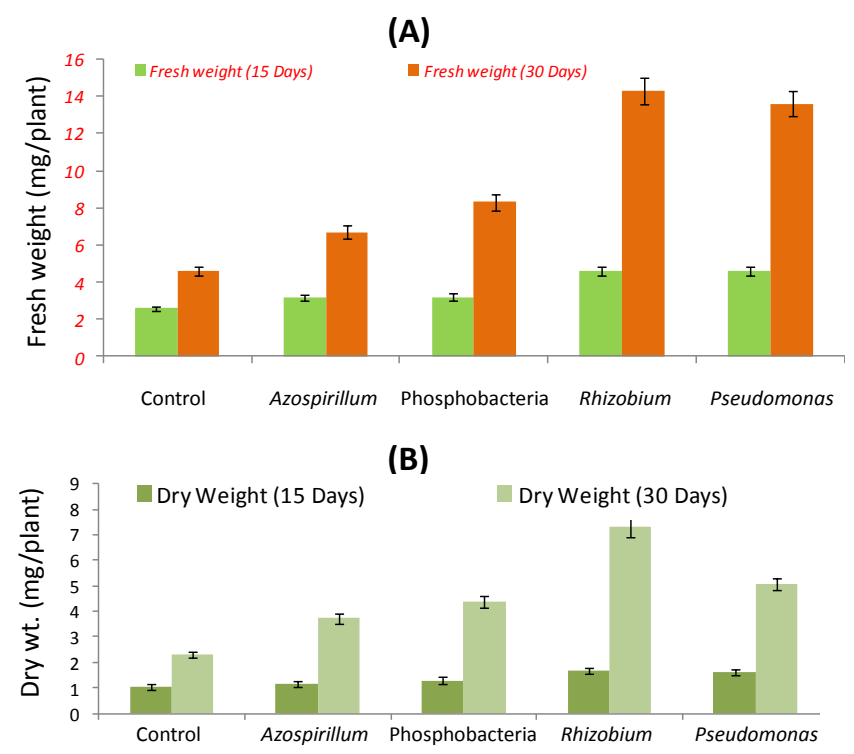

Fig. 3: Effect of different soil amendments on (A) fresh weight and (B) dry weight of L. esculentum.

As the analysis of variance indicated in Figs. 5 (A, B and $\mathrm{C}$ ), protein, total sugar and starch contents recorded increase due to application of Azospirillum, Phosphobacteria, Rhizobium and Pseudomonas fluorescens over control. Maximum protein, total sugar and starch contents was observed in single application of soil amendment Rhizobium on 15 and 30 DAS with respect to control. Minimum protein, total sugar and starch contents was recorded from the untreated plants. This work agrees with the work of Rahmani et al. (2008) who indicated that nitrogen is the most important element in protein synthesis and its increase in optimum conditions increases the amount of protein. Also the obtained findings are in line with Tiwari (2017) who reported an increment of total sugar and carbohydrates content with the mixed culture of Azotobacter and Rhizobium sp. treatment $\left(\mathrm{T}_{4}\right)$ increased reducing and non-reducing sugars quantity. Non-reducing sugar contents were increased due to the possible reasons to enhance in carbon fixation, activation of enzymes and improved photosynthetic rate. 


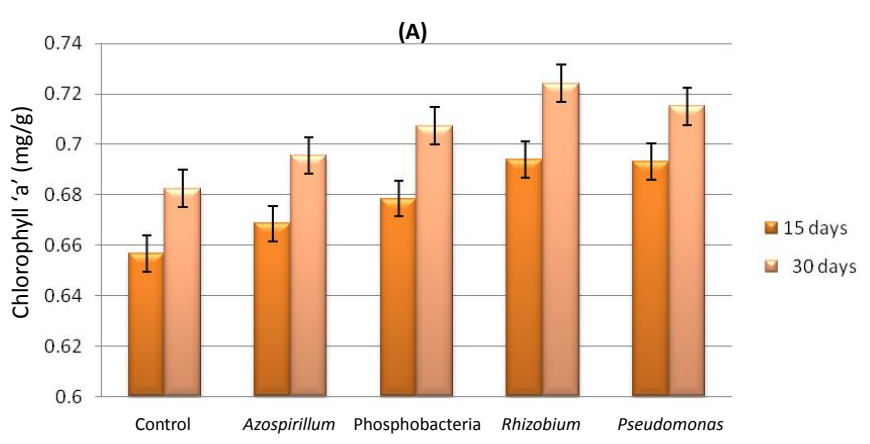

(B)

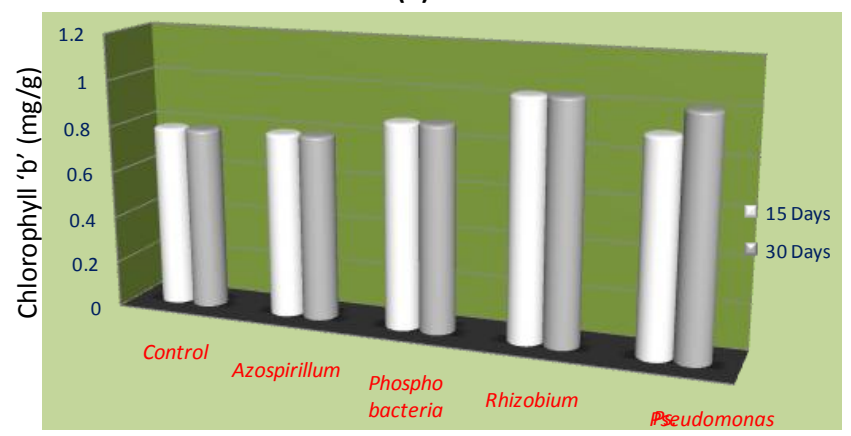

Fig. 4: Effect of different soil amendments on

(A) Chlorophyll 'a' and (B) Chlorophyll 'b' contents in L. esculentum leaves.
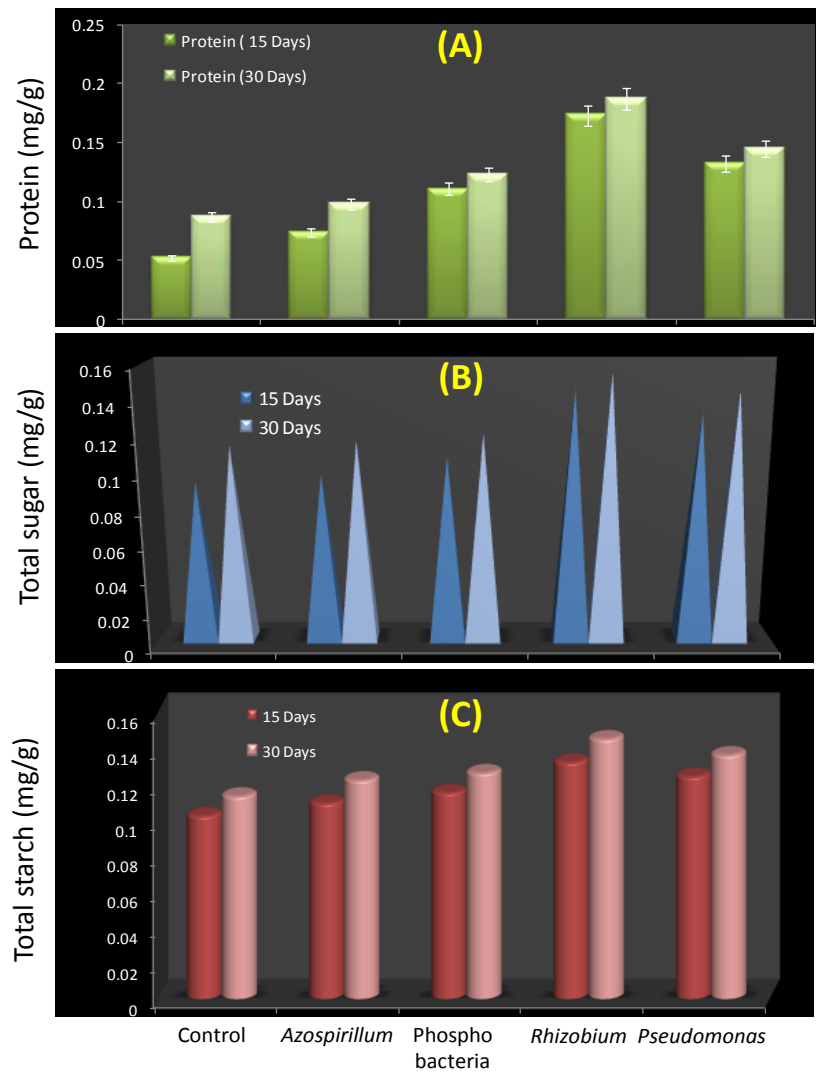

Fig. 5: Effect of different soil amendments on (A) protein, (B) total sugars and (C) total starch contents of L. esculentum.

\section{Conclusions}

From the results of this study, it is clear that biofertilizers show better results compared to that of the control experiments. Based on the results of the present study, it can be stated that the Rhizobium exhibited better results followed by Pseudomonas aeruginosa and phosphobacteria. The enhanced growth of tomato is attributed to the addition of biofertilizers and therefore can be used as biofertilizer for the cultivation of tomato crops. Further combinatorial effect of these biofertilizers and field trial evaluations enrich the effectiveness of crop growth and yield.

\section{Conflict of interest statement}

Authors declare that they have no conflict of interest.

\section{References}

Arnon, D.I., 1949. Copper enzymes in isolated chloroplasts. photophenoloxidase in Beta vulgaris. Plant. Physiol., 24: 1-5.

Dubois, M., Gilles, K.A., Hamilton, J.K., Rebers, P.A., Smith, F., 1956. Colorimetric method for determination of sugars and related substances. Anal. Chem., 28: 350-356.

Farfour, A. S., 2013. Enhancement of the growth and phenolic content of faba bean (Vicia faba L.) by applying some biofertilizer agents. J. Food Stud., 2(2): 20 .

Ilyas, S., Asie, K.V., Sutariati, G.A.K., 2014. Biomatri conditioning or biopriming with biofungicides or biological agents applied on hot pepper (Capsicum annuum L.) seeds reduced seed borne Colletotrichum capsici and increased seed quality and yield. In: XXIX International Horticultural Congress on Horticulture: Sustaining Lives, Livelihoods and Landscapes (IHC2014): 1105. pp. 89-96.

Kalaiarasi, R., Sivakumar, T., 2014. Effect of bacterial biofertilizers on the growth and yield of Phaseolus vulgaris L. Int. J. Adv. Res. Biol. Sci., 1(8): 56-73.

Lowry, O.H., Rosebrough, N.J., Farr, A.L., Randall, R.J., 1951. Protein measurement with folin phenol reagent. J. Biol. Chem., 193: 265-275.

Mie, A., Andersen, H.R., Gunnarsson, S., Kahl, J., Kesse-Guyot, E., Rembiałkowska, E., Quaglio, G., Grandjean, P., 2017. Human health implications of organic food and organic agriculture: a comprehensive review. Environ. Health, 16(1): 1-11. 
Nalawde, A.A., Bhalerao, S.A., 2015. Comparative account of effect of biofertilizers on the growth and biochemical parameters of Vigna mungo (L.) Hepper. Int. J. Adv. Res. Biol. Sci., 2(5): 62-66.

Nelson, N., 1944. A photometric adaptation of the Somogyi's method for the determination of reducing sugar. Anal. Chem., 31: 426-428.

Rahmani, N., Valadbighi, S.A., Daneshian, J., Bidgholi, V.M., 2008. Effect of different levels of drought stress and nitrogen on oil yield in evergreen herb (Calendula officinalis L.). J. Res. Arom. Plant Iran., 24(1): 101-108.

Reddy, S., Singh, A. K., Masih, H., Benjamin, J. C., Ojha, S. K., Ramteke, P. W., Singla, A., 2018. Effect of Azotobacter sp. and Azospirillum sp. on vegetative growth of tomato (Lycopersicon esculentum). J. Pharmacogn. Phytochem., 7(4): 2130-2137.

Sameh, H., Youseif, F. H., El-Megeed, A., Saleh, A. S.,
2017. Improvement of faba bean yield using Rhizobium/Agrobacterium inoculant in low-fertility sandy soil. Agronomy, 7(1): 2.

Tiwari, S., Chauhan, R. K., Singh, R., Shukla, R., Gaur, R., 2017. Integrated effect of Rhizobium and Azotobacter cultures on the leguminous crop, black gram (Vigna mungo). Adv. Crop Sci. Tech., 5(3): 289-297.

Yadav, A.N., Kumar, R., Kumar, S., Kumar, V., Sugitha, T., Singh, B., Chauhan, V.S., Dhaliwal, H.S., Saxena, A.K., 2017. Beneficial microbiomes: Biodiversity and potential biotechnological applications for sustainable agriculture and human health. J. Appl. Biol. Biotechnol., 5(6): 45-57.

Zheng, X., Fan, J., Cui, J., Wang, Y., Zhou, J., Ye, M., Sun, M., 2016. Effects of biogas slurry application on peanut yield, soil nutrients, carbon storage, and microbial activity in an Ultisol soil in southern China. J. Soils Sedim., 16: 449-460.

\section{How to cite this article:}

Prabakaran, S., Bakiyaraj, R., Baskaran, L., Mahakavi, T., 2021. Effect of biofertilizers on growth, photosynthetic and biochemical parameters of tomato (Lycopersicon esculentum Mill.). Int. J. Curr. Res. Biosci. Plant Biol., 8(3): 10-14. doi: https://doi.org/10.20546/ijcrbp.2021.803.002 